\title{
Yüksek Doz Hızlı Brakiterapi Cihazının Kalite Kontrol Testlerinde 2D-Array İyon Odası Sisteminin Kullanılabilirliği: Dozimetrik Fizibilite Çalışması*
}

\author{
Fatih BİLTEKIN \\ Hacettepe Üniversitesi Tıp Fakültesi Radyasyon Onkolojisi Anabilim Dalı, Ankara.
}

\begin{abstract}
ÖZET
Çalışma kapsamında yüksek doz hızlı (YDH) brakiterapi (BRT) cihazına ait kalite kontrol (KK) testlerinde 2D-Array iyon odası sisteminin kullanılabilirliği araştııılmıştır. Ölçümler kliniğimizde kullanılmakta olan GammaMed Plus ${ }^{\mathrm{TM}_{\mathrm{iX}}}$ YDH BRT cihazında PTW Seven29 2DArray iyon odası sistemi kullanılarak gerçekleş̧irilmiş̧tir. Mekanik KK testleri; kaynak pozisyon doğruluğu, lineerite ve farklı adım mesafeleri için cihazın tekrarlanabilirliği olmak üzere üç farklı seride alınmıştır. Ölçümlerin ikinci aşamasında ise 2D-Array iyon odası sisteminin dozimetrik KK testlerinde kullanılabilirliğini araştırmak amacı ile aktivite, gün içerisindeki aktivite değişiminin tedavi dozuna etkisi, planlanan ve ölçülen doz dağılımlarının uyumu olmak üzere üç farklı seride ölçümler gerçekleştirilmiştir. Mekanik KK testleri için, 2D-Array iyon odası sistemi $0,5 \mathrm{~mm}$ 'nin altında hassasiyetle kaynak pozisyon hatalarını tespit edebilmektedir. Farklı adım mesafeleri için uygulanan referans tedavi planlanlamalarının tekrarlanabilirliği 2D-Array iyon odası sistemi ile teyit edilmiştir. 4 ile 100 saniye arasındaki maksimum rölatif farkl11ı \%1'in altında bulunmuştur. Dozimetrik KK testlerinde ise 2D-Array iyon odası sistemi ile ölçülen aktivite değeri gerçek değer ile \%3,3 içerisinde uyumlu bulunmuştur. Ayrıca gün içindeki aktivite değişiminin tedavi dozuna etkisini kontrol etmek amacı ile 1 saat ara ile tekrarlanan 10 ölçüme ait gama analizi sonucu $3 \mathrm{~mm}$ uyum mesafesi (UM) ve \%3 doz farkı (DF) için \%98'in üzerinde bulunurken, 1 mm UM ve \%1 DF kriteri üzerinden değerlendirme yapıldığı zaman 6 saat ve 8 saat sonra alınan ölçümlere ait gama analizi sonucu sırası ile \%85.7 ve \%84.9 olarak bulunmuştur. 2D-Array iyon odası sistemi BRT uygulamaları için cihaz tabanlı KK testlerinde tercih edilebilir bir sistem performansina sahiptir.
\end{abstract}

Anahtar Kelimeler: Brakiterapi, Kalite Kontrol, Gama Analizi, 2D-Array.

Use of 2D-Array Ionization Chamber in the Quality Control of High Dose Rate Brachytherapy Treatmet Unit:

Dosimetric Feasibility Study

\begin{abstract}
The main aim was to investigate the feasibility of 2D-Array ionization chamber system for high-dose-rate (HDR) brachytherapy (BRT) quality control (QC) tests. All measurements were performed with PTW Seven29 2D-Array in GammaMedPlusTM iX HDR-BRT unit. Mechanical QC tests consisted of three stages: source-dwell positioning accuracy, reproducibility of source position for different step-size, linearity of system with changing dwell-time. In dosimetric QC tests; activity of radioactive source, dosimetric effects of activity change in a day for different period of time and coincidence of planned and measured dose distribution were analyzed. For mechanical QC tests, 2DArray was found to be sensitive to positional errors lower than $0.5 \mathrm{~mm}$. In the second part, reproducibility of the treatment planning with different step sizes was confirmed. The maximum relative differences for different irradiation time (range: 4-100 seconds) were measured lower than 1\%. In dosimetric QC tests, measured activity with 2D-Array was found 3.3\% lower than the reference activity given in treatment unit. Additionally, in order to control the effect of the change in activity in a day for different period of time, the gamma analysis of 10 measurements repeated with an interval of 1 hour was found to be over $98 \%$ for $3 \mathrm{~mm}$ distance to agreement (DTA) and $3 \%$ dose difference (DD). Hovewer, gamma analysis of the measurements taken after 6 and 8 hours was found as $85.7 \%$ and $84.9 \%$ for $1 \mathrm{~mm}$ DTA and 3\% DD, respectively. The use of 2D system is a reliable and cost-effective method to perform comprehensive quality control of HDR-BRT unit.
\end{abstract}

Key Words: Brach therapy, Quality Assurance, Gamma Analysis, 2D-Array.

Geliş Tarihi: 27.Aralık.2019

Kabul Tarihi: 17.Nisan.2020

* 12. Ulusal Radyasyon Onkolojisi Kongresi'nde (21-24 Nisan 2016, Antalya) sözlü bildiri olarak sunulmuştur.

Dr. Fatih BILTEKIN

Hacettepe Üniversitesi Tıp Fakültesi,

Radyasyon Onkolojisi Anabilim Dalı, Ankara.

Tel.: 05076849859

E-posta: fatih.biltekin@hacettepe.edu.tr
Brakiterapi (BRT) radyoaktif kaynakların direk tümör içerisine veya çevresine yerleştirildiği internal radyoterapi tekniğidir ${ }^{1}$. BRT uygulamaları kaynak yerleştirme tekniklerine göre intrakaviter, interstisyel, intralüminal, intravasküler ve yüzeyel (mold) olmak üzere beş ana başlık altında sınıflandırılırken, implant tiplerine göre geçici ve kalıcı implant olarak iki farklı şekilde uygulanabilmektedir. Doz hızı sınıflandırması açısından ise "International Commission on Radiation 
Unitsand Measurements" (ICRU) 38 no'lu raporuna göre düşük doz hızlı (DDH), orta doz hızlı (ODH) ve yüksek doz hızlı (YDH) ve puls doz hızlı (PDH) olmak üzere dört gruba ayrılmaktadır ${ }^{2}$.

BRT uygulamalarında iletilen doz ters kare kanununa bağlı olarak kaynaktan uzaklaştıkça hızlı bir şekilde azalmaktadır. Bu sayede hedef bölgeye yüksek tedavi dozu verilirken, çevre normal dokular eksternal radyoterapiye (ERT) kıyasla daha iyi korunabilmektedir ${ }^{3}$. BRT uygulamaları sağlamış olduğu tüm bu avantajlar nedeni ile günümüzde tek başına veya ERT sonrasında ek doz uygulaması olarak ya da rekürren hastalıkta kurtarma tedavisi amacı ile yaygın bir şekilde kullanılmaktadır ${ }^{4}$.

Günümüzde BRT uygulamalarında üç boyutlu BRT (3B-BRT) ve görüntü kılavuzluğunda BRT (GK-BRT) gibi yeni tedavi modalitelerine geçiş ile birlikte volümetrik olarak hedefin doğru tanımlanmasının yanında, tedavi planının belirlenen kriterler dahilinde uygulanabilirliği tedavi etkinliği açısından daha büyük önem kazanmıştır. $\mathrm{Bu}$ nedenle uygulama karmaşıklığı ve radyoaktif kaynak kullanımından dolayı BRT'de kapsamlı bir kalite kontrol (KK) programının uygulanmas1 hem tedavi etkinliği ve hem de radyasyon kazalar1nın önlenmesi açısından tedavinin önemli bir parçasını oluşturmaktadır ${ }^{1}$. KK testlerinin temel amacı ise cihazın ve yardımcı diğer ekipmanların belirli periyotlarda kontrollerinin yapilarak uluslararası protokollerde belirlenen standartlara uygunluğunun test edilmesi ve cihazın rutin klinik uygulamalarda kullanılabilmesi için hazır halde bulundurulmasını sağlamaktır. KK programı kapsamında yapılması gereken testler ise tüm sistemler için standart olabileceği gibi kullanılan cihaza bağlı olarak da farklılık gösterebilmektedir. Günümüzde bu KK testlerinin çoğunluğunda özel olarak dizayn edilmiş kuyu tipi iyon odası sistemleri, radyografik veya radyokromik filmler kullanılmaktadır. Bizim çalışmamızda ise HDR BRT cihazına ait KK testlerinde PTW Seven29 2D-Array iyon odas1 sisteminin (PTW, Freiburg, Germany) kullanılabilirliği kapsamlı bir şekilde incelenmiştir. 2D-Array iyon odası sistemi ERT uygulamalarında hasta tabanlı KK ölçümlerinde yaygın bir şekilde kullanılmaktadır. Ancak, mevcut sistemin BRT KK testlerinde kullanımına ilişskin standart bir yaklaşım bulunmamaktadır. $\mathrm{Bu}$ nedenle bu çalışma kapsamında iki boyutlu (2B) iyon odas1 sisteminin BRT'de rutin mekanik ve dozimetrik KK testlerinde uygulanabilirliği ve güvenilirliği test edilmiştir. Bu sayede klinikte mevcut bulunan 2B dozimetrik bir sistem ile daha kısa sürede $\mathrm{KK}$ testlerinin yapılabilmesi ve özellikle de mekanik KK testlerinde film dozimetre kullanımından kaynaklı maliyetin ortadan kaldırılması amaçlanmıştır.

\section{Gereç ve Yöntem}

Ölçümler Hacettepe Üniversitesi Radyasyon Onkolojisi Anabilim Dalı'nda kullanılmakta olan GammaMedPlus ${ }^{\mathrm{TM}} \mathrm{iX}$ BRT cihazında (Varian Medical Systems, Palo Alto, USA) PTW Seven29 2D-Array iyon odası sistemi kullanılarak gerçekleştirilmiştir. VarianGammaMedPlus ${ }^{\mathrm{TM}_{\mathrm{iX}}}$ cihazı uzaktan kumandalı sonradan yüklemeli HDR ve PDR yapabilme özelliğine sahiptir. Cihaz için üretilen Ir-192 radyoaktif kaynağı $0,6 \mathrm{~mm}$ çap ve $3,5 \mathrm{~mm}$ aktif uzunluğa sahip olup $0,9 \mathrm{~mm}$ çapında ve $4,52 \mathrm{~mm}$ uzunluktaki paslanmaz çelik kapsül tabaka ile kaplanmıştır ve 0,9 mm çapında bir telin ucuna bağlıdır. Ölçümlerde kullanılan 2DArray iyon odası sistemi ise $27 \times 27$ 'lik bir matriks şeklinde dizili içi hava dolu 729 adet iyon odasından oluşmaktadır. Paralel plakalı kübik iyon odalarının boyutu $5 \mathrm{~mm}$ x $5 \mathrm{~mm}$ x $5 \mathrm{~mm}$ ve aktif hacmi 0,125 cc olup iyon odaları merkezleri arasındaki mesafe 10 mm'dir. Analiz aşamasında ise PTW VeriSoftv.5.1 (PTW, Freiburg, Germany) yazılımı kullanılmıştır.

Mevcut çalışma kapsamında belirtilen özelliklere sahip 2D-Array iyon odası sisteminin BRT KK testlerinde kullanılabilirliğini araştırmak amacı ile mekanik ve dozimetrik KK testleri olmak üzere iki farklı şekilde ölçümler alınmıştır.

\section{Mekanik KK Testleri}

Mekanik KK testlerinde kaynak pozisyon doğruluğu, lineerite, farklı adım mesafeleri için cihazın stabilitesi ve kaynak pozisyonunun tekrarlanabilirliği olmak üzere üç farklı aşamada ölçümler gerçekleştirilmiştir. Ölçümlerin ilk aşamasında Şekil 1'de gösterildiği üzere aplikatör probunun içerisine X-ışını işaretleyici "X-ray marker" yerleştirilerek işaretleyicilerin orta noktası detektörün merkezine gelecek şekilde pozisyonlandırıldı ve radyografik görüntüleme yöntemi ile duruş pozisyonları tespit edildi. Ardından Varian Brachy Vision tedavi planlama sisteminde (TPS) (Varian Medical Systems, Palo Alto, USA) Şekil 2'de gösterildiği üzere farklı kaynak pozisyonları için planlamalar yapılarak tedavi cihazına aktarıldı ve mevcut planlamalar tedavi cihazında ışınlanarak radyografi ile belirlenen pozisyonlar ve gerçek kaynak pozisyonları arasındaki pozisyonlandırma hatası maksimum doz noktası referans alınarak analiz edildi. Ölçümlerin ikinci aşamasında $1 \mathrm{~cm}, 0,5 \mathrm{~cm}, 0,3 \mathrm{~cm}$ ve $0,1 \mathrm{~cm}$ olmak üzere 4 farklı adım mesafesi için yapılan planlamaların tekrarlanabilirliği ve cihazın stabilitesi gama analizi yöntemi kullanılarak kontrol edilmiştir. Bu aşamada gama analizinde $1 \mathrm{~mm}$ uyum mesafesi (UM) ve \%1 doz farkı (DF) kriterleri üzerinden karşılaştırma yapılmıştır ve ilk ışınlama referans olarak alınmıştır. Üçüncü aşamada ise Şekil 3 'te belirlenen referans kaynak pozisyonunda farklı zaman dilimlerinde(4, 8, $10,15,20,40,50,75$ ve 100 saniye) ölçümler alınarak 


\section{Brakiterapi Cihazının Testlerinde 2D-Array İyon Odası Sisteminin Kullanımı}

okuma değerleri 100 saniyede okunan değere normalize edilmiştir ve farklı 1şınlama süreleri için cihazın lineeritesi incelenmiştir.

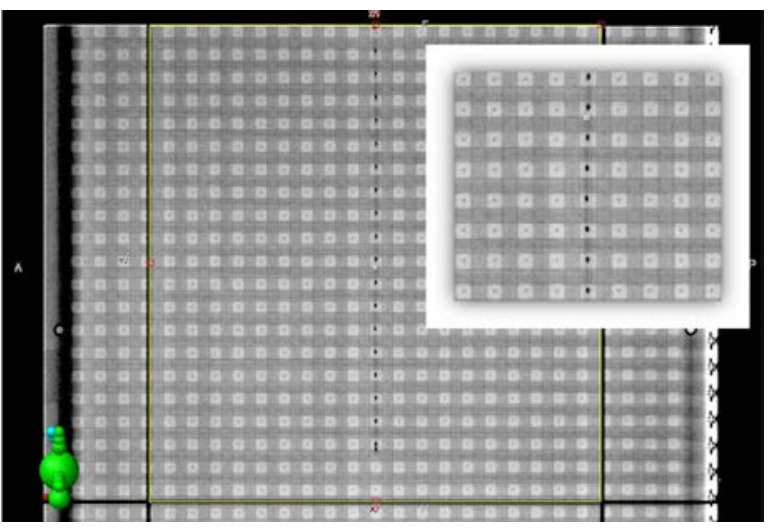

Sekil 1.

$X$-ışını işaretleyici kullanılarak alınan radyografi görüntüsü.

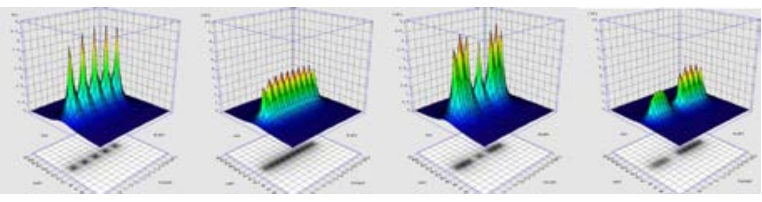

Şekil 2.

Kaynak pozisyon doğruluğu testi için 2D-Array iyon odası sistemi kullanılarak farklı mesafe aralıklarında alınan ölçümler.

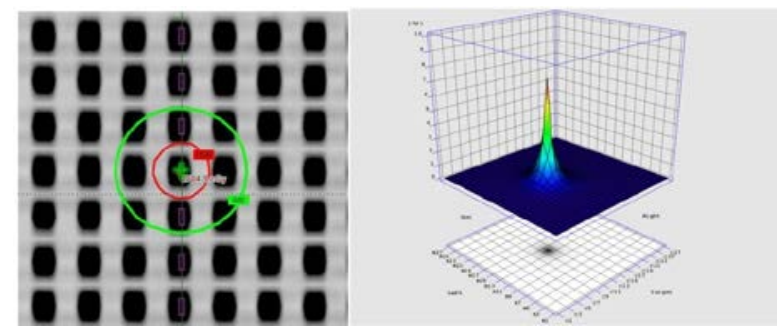

Şekil 3.

Lineerite ölçümü için; a) örnek tedavi planlamasına ait doz dağılımı ve b) 2D-Array iyon odası sistemi ile alınan ölçüm görüntüsü.

\section{Dozimetrik KK Testleri}

Dozimetrik KK testlerinde ise kaynak aktivitesi, gün içerisindeki aktivite değişiminin tedavi dozuna etkisi ve TPS'de yapılan tedavi planının uygulanabilirliği olmak üzere üç farklı aşamada ölçümler gerçekleştirilmiştir. Kaynak aktivitesi ölçümü için 2D-Array iyon odası sisteminin merkezinde yer alan iyon odası PTW 0,6 cc farmer iyon odası ile çapraz kalibrasyon yapılarak havada $10 \mathrm{~cm}$ mesafede "International Atomic Energy Agency" (IAEA) tarafindan yayınlanan TECDOC 1274 no'lu raporunda ${ }^{5}$ belirtilen referans koşullarda ölçümler alınmıştır ve ölçüm sonuçları 0,6 cc iyon odası ile elde edilen aktivite değeri ve gerçek kaynak aktivitesi ile karşılaştırılmıştır. Ölçümlerin ikinci aşamasında gün içerisindeki aktivite değişiminin tedavi dozuna etkisini araştırmak amacı ile Şekil 4'te gösterildiği üzere TPS'de hazırlanan örnek bir tedavi planı cihaza aktarılarak aynı gün içerisinde birer saat ara ile toplam 10 ölçüm alınmıştır ve her bir ölçüm iki defa tekrarlanmıştır. Değerlendirme aşamasinda $1 \mathrm{~mm}$ UM / \%1 DF ve $3 \mathrm{~mm}$ UM / \%3 DF olmak üzere iki farklı kriter üzerinden gama analizi yapılmıştır. Ölçümlerin son aşamasında ise özel olarak dizayn edilmiş KK fantomu ve aplikatörü kullanılarak Şekil 5 'te gösterilen referans koşullarda ve homojen ortamda TPS'de referans bir tedavi planı oluşturulmuştur. Oluşturulan tedavi planı BRT cihazında 1şınlanarak TPS'den elde edilen 2B doz haritası ile Gafkromik EBT3 film (Ashland Specialty Ingredients, NJ, USA) ve 2D-Array iyon odası sistemi tarafından ölçülen doz haritaları gama analizi yöntemi ile karşılaştırılarak homojen fantom geometrisinde TPS ile tedavi cihazı arasındaki uyumluluk kontrol edilmiştir. Gama analizi kriteri olarak 3mm UM ve \%3 DF kriteri kullanılmıştir.

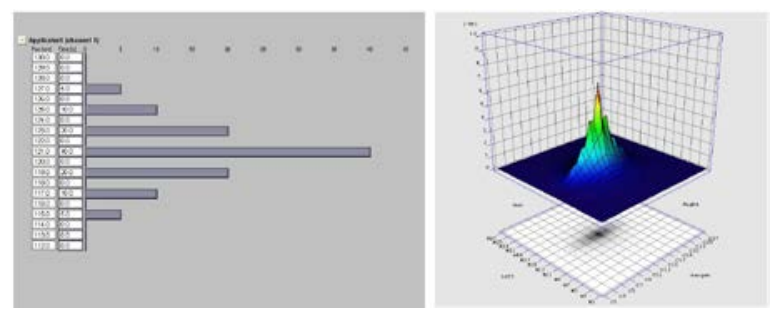

Şekil 4.

Gün içerisindeki aktivite değişiminin tedavi dozuna etkisini değerlendirmek amacı ile yapılan tedavi planlamasına ait; a) kaynak duruş pozisyonları ve süreleri, b) 2D-Array iyon odası sistemi ile alınan ölçüm görüntüsü.

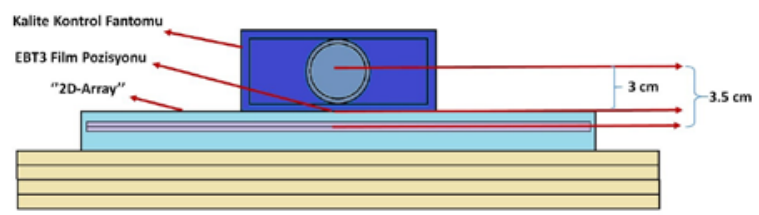

Sekil 5 .

Gafkromik EBT3 film ve 2D-Array iyon odası sistemi ile $2 B$ doz ölçümüne ait set-up.

\section{Bulgular}

\section{Mekanik KK Testleri}

Kaynak pozisyon doğruluğu için yapılan ölçüm sonuçları analiz edildiğinde 2D-Array iyon odası sisteminin HDR tabanlı BRT uygulamalarında kaynak pozisyon testi için milimetrenin altında hassasiyetle kullanılabileceği gösterilmiştir. Mevcut çalışmada pozisyonlandırma hatası için maksimum doz noktası ile detektör 
orta noktası arasındaki mesafe otomatik olarak üst üste çakıştırıldığında maksimum hata yaklaşık $0,4 \mathrm{~mm}$ (tolerans limiti $\leq 2 \mathrm{~mm}$ ) olarak ölçülmüştür. Verisoft yazılımı ayrıca Şekil 6'da gösterildiği üzere kaynak pozisyonlarının gri skala, izodoz çizgisi veya doz boyama şeklinde analiz edilebilmesine olanak sağlamaktadir.

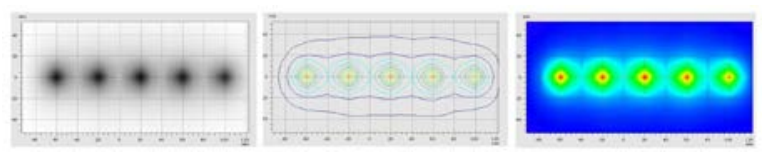

Şekil 6.

Kaynak pozisyon doğruluğu testi; a) gri skala, b) izodoz çizgisi ve c) doz boyama görüntüsü.

Farklı adım mesafesi için yapılan sıralı üç ölçüm ise gamma analiz yöntemi ile kendi içerisinde karşılaşt1rıldığında (1 mm UM ve \%1 DF) $1 \mathrm{~cm}, 0,5 \mathrm{~cm}$ ve 0,3 cm'de gama geçme oranı \%100 ve $0,1 \mathrm{~cm}$ adım mesafesinde ise en düşük gama analizi değeri \%99 olarak bulunmuştur. Analiz sonuçları referans alındığında mevcut sistem için ardışık üç 1șınlamanın belirlenen kriterler doğrultusunda birbiri ile uyumlu olduğu gözlenmiştir.

Cihazın 4-100 saniye zaman aralığındaki lineeritesi ve ölçümler arasındaki yüzde fark Tablo I’de gösterilmiştir. Ölçüm sonuçları 100 saniyeye normalize edildiğinde maksimum farklılık \%1 olarak ölçülmüştür. Maksimum farklılığı analiz edebilmek için hesaplamalarda kaynağın geçiş süresi hesaba katılmamıştır. Geçiş süresinin göz önünde bulundurulması halinde ise maksimum farklılık tüm ölçümler için \%0.4'ün altında bulunmuştur.

Tablo I. Zamana bağlı olarak rölatif doz değerlerindeki değişim.

\begin{tabular}{|l|c|c|c|c|c|c|c|c|c|}
\hline $\begin{array}{l}\text { Işınlama } \\
\text { Süresi (saniye) }\end{array}$ & 4 & $\mathbf{8}$ & 10 & 15 & $\mathbf{2 0}$ & $\mathbf{3 0}$ & $\mathbf{5 0}$ & $\mathbf{7 5}$ & $\mathbf{1 0 0}$ \\
\hline $\begin{array}{l}\text { Rölatif Okuma } \\
\text { Değeri (cGy) }\end{array}$ & 0,04 & 0,08 & 0,1 & 0,15 & 0,2 & 0,3 & 0,499 & 0,749 & 1 \\
\hline $\begin{array}{l}\text { Yüzde Fark } \\
(\%)^{*}\end{array}$ & 1 & 0,5 & 0,4 & 0,13 & 0,1 & 0,3 & 0,18 & 0,17 & $\ldots---$ \\
\hline
\end{tabular}

\section{Dozimetrik KK Testleri}

Aktivite ölçümü için 2D-Array iyon odası sisteminin merkezi iyon odası kullanılarak havada $10 \mathrm{~cm}$ mesafede maksimum ölçüm noktasında üç adet ölçüm alınmıștır. Benzer ölçümler 0,6 cc silindirik iyon odası ile tekrarlanarak ölçüm sonuçları tedavi cihazında belirtilen referans aktivite değeri ile karşılaştırılmıştır. Ölçümlerin ilk aşamasında 2D-Array iyon odasının 0,6 cc iyon odası ile $6 \mathrm{MV}$ foton enerjisi kullanılarak $5 \mathrm{~cm}$ derinlikte çapraz kalibrasyonu yapılmıştır. Ayrıca çapraz kalibrasyon işlemi BRT cihazında $0,5 \mathrm{~cm}$ derinlikte tekrarlanarak 2D-Array iyon odası sisteminin merkezi detektörü için kalibrasyon faktörü hesaplanmıştır. Ölçümler sonucunda 0,6 cc silindirik iyon odası ve 2D-Array detektör kullanılarak hesaplanan aktivite değeri referans aktivite değerinden sirası ile $\% 2,6$ ve $\% 3,3$ (tolerans limiti $\leq \pm \% 5$ ) daha düşük ölçülmüştür. Ayrıca 2D-Array ve 0,6 cc iyon odası sistemi ile elde edilen verilerin \%1'in içerisinde uyumlu olduğu bulunmuştur

GammaMedPlus ${ }^{\mathrm{TM}} \mathrm{iX}$ cihazında aktivite düzeltmesi sistem tarafından günlük olarak yapılmaktadır. Bu nedenle de gün içerisindeki aktivite değişiminin tedavi dozuna etkisi hesaba katılmamaktadır. Özellikle parsiyel meme 1şınlamaları gibi 6-8 saat ara ile günde iki defa uygulanan tedavi yöntemlerinde gün içerisindeki aktivite değişiminin iletilen tedavi dozuna etkisinin dikkate alınması uygulanan toplam doz üzerindeki belirsizliği düşürme adına önem taşımaktadır. Çalışma kapsamında Şekil 5 'te belirtilen tedavi planlaması kullanılarak aynı gün içerisinde birer saat ara 10 ölçüm alınmıştır ve ölçüm sonuçları ilk ışınlama ile karşılaştırılmıştır. 3mm UM ve \%3 DF kriteri kullanılarak gama analizi sonuçları değerlendirildiğinde gün içerisindeki aktivite değişiminin tedavi dozu üzerine etkisi klinik kabul kriterleri içerisinde bulunmuştur (Tablo II). Ancak, 1mm UM ve \%1 DF kriteri üzerinden değerlendirme yapıldığı zaman 6 ve 8 saat sonra alınan ölçümlere ait gama analizi sonuçları sırası ile \%85.7 ve \%84.9 olarak saptanmıştır. Bu sonuçlar aynı gün içerisindeki aktivite değişiminin tedavi dozuna etkisinin tamamen göz ardı edilemeyeceğini ve günde iki fraksiyon yapılan uygulamalar için tedaviler arasında geçen sürenin ve aktivite düzeltmesi sonrasında geçen zaman diliminin dikkate alınması gereken bir faktör olduğunu göstermektedir. 2B gama analizi sonuçlarına ek olarak nokta doz değerleri Tablo II'de ayrıntılı olarak sunulmuştur.

Tablo II. Aktivite değişiminin doz değerlerine ve gamma analizi sonucuna etkisi.

\begin{tabular}{|c|c|c|c|c|c|c|c|c|c|}
\hline \multirow{2}{*}{$\begin{array}{l}\text { Aktivite } \\
9.782 \mathrm{Ci}\end{array}$} & \multicolumn{7}{|c|}{ Kaynak Pozisyonu (cm) } & \multirow{2}{*}{\multicolumn{2}{|c|}{$\begin{array}{c}\text { Gamma Analiz } \\
(\%)^{\star *}\end{array}$}} \\
\hline & 127 & 125 & \begin{tabular}{|l|}
123 \\
\end{tabular} & \begin{tabular}{|l|}
121 \\
\end{tabular} & 119 & 117 & 115 & & \\
\hline Ölçüm* & \multicolumn{7}{|c|}{ Doz (Gy) } & \begin{tabular}{|c|}
$1 \mathrm{~mm}$ \\
UM/ $\%$ \\
$1 \mathrm{DF}$ \\
\end{tabular} & \begin{tabular}{|c|}
$3 \mathrm{~mm}$ \\
UM/ \%3 \\
DF
\end{tabular} \\
\hline 1 & 2,625 & 4,31 & 4,489 & 7,061 & 4,072 & 4,136 & 2,309 & ref. & ref. \\
\hline 2 & 2,63 & 4,322 & 4,478 & 7,04 & 4,059 & 4,137 & 2,319 & 96 & 100 \\
\hline 3 & 2,577 & 4,288 & 4,437 & 7,035 & 4,062 & 4,092 & 2,312 & 92,1 & 99,2 \\
\hline 4 & 2,572 & 4,278 & 4,392 & 7,041 & 4,067 & 4,119 & 2,313 & 92,1 & 99,2 \\
\hline 5 & 2,574 & 4,273 & 4,396 & 7,009 & 4,05 & 4,101 & 2,304 & 92,1 & 98,4 \\
\hline 6 & 2,567 & 4,26 & 4,388 & 7,021 & 4,048 & 4,103 & 2,291 & 86,5 & 99,2 \\
\hline 7 & 2,559 & 4,253 & 4,376 & 7,032 & 4,051 & 4,109 & 2,303 & 85,7 & 99,2 \\
\hline 8 & 2,558 & 4,256 & 4,377 & 7,007 & 4,043 & 4,102 & 2,306 & 85,7 & 98,4 \\
\hline 9 & 2,564 & 4,259 & 4,385 & 6,997 & 4,041 & 4,096 & 2,309 & 84,9 & 99,2 \\
\hline 10 & 2,56 & 4,257 & 4,392 & 6,961 & 4,023 & 4,093 & 2,31 & 85,7 & 99,2 \\
\hline
\end{tabular}

* 1 saat ara ile alınan ölçüm sıralaması

** 1. Ölçüm referans olarak alınmıştır

Ölçümlerin son aşamasında ise TPS tarafından hesaplanan ve 2D-Array iyon odası sistemi ile ölçülen doz haritalarının uyumu analiz edilmiştir. Şekil 6'da göste- 


\section{Brakiterapi Cihazının Testlerinde 2D-Array İyon Odası Sisteminin Kullanımı}

rilen fantom geometrisi üzerinde tedavi planlaması yapılarak ilgili derinliklerde Gafkromik EBT3 film ve 2D-Array iyon odası sistemi ile ölçümler alınmıştır. Gamma analizi sonuçları Tablo III'te ayrıntılı olarak gösterilmiştir.

Tablo III. Homojen ortamda EBT3 Film ve 2D-Array iyon odası ile alınan ölçümlerin TPS doz dağılımı ile karșılaștırması.

\begin{tabular}{|c|c|c|}
\hline $\begin{array}{c}\text { Gamma Analizi } \\
\text { Kriterleri }\end{array}$ & Gafkromik EBT3 & 2D-Array \\
\hline 3 mm UM / \%3 DF & $93,10 \%$ & $94,80 \%$ \\
\hline 3 mm UM / \%5 DF & $94,30 \%$ & $97,40 \%$ \\
\hline $\mathbf{5}$ mm UM / \%3 DF & $94,40 \%$ & $100 \%$ \\
\hline 5 mm UM / \%5 DF & $94,60 \%$ & $100 \%$ \\
\hline
\end{tabular}

\section{Tartışma}

BRT uygulamalarında planlanan ve iletilen doz arasındaki uyum tedavinin etkinliği açısından büyük önem taşımaktadır. Günümüzde BRT'de minyatür X1Şını tabanlı uygulamaların haricinde halen radyoaktif kaynakların kullanımı yaygın bir şekilde devam etmektedir. Ancak "The International Commission on Radiological Protection" (ICRP) tarafindan hazırlanan ve 2005 yılında yayınlanan 97no'lu raporun verilerine göre BRT uygulamalarında belirtilen tarihe kadar kayıt altına alınmış 500'ün üzerinde radyasyon kazası olduğu bildirilmiştir ${ }^{6}$. Günümüzde BRT'de kompleks tedavi modalitelerinin kullanımının yaygın hale gelmesi ile birlikte hem tedavinin etkinliği, hem de radyasyon çalışanlarının ve toplumun diğer bireylerinin güvenliği açısından uluslararası protokoller doğrultusunda kapsamlı bir KK programının uygulanması gereklilik haline gelmiştir. Ayrıca, ERT uygulamalarından farklı olarak BRT'de doz gradyanının çok yüksek olması ve kaynak yakınında yüksek doz bölgelerinin oluşmasına bağlı olarak daha katı tolerans limitlerinin uygulanması gerekmektedir. Literatürde, BRT'de KK ile ilgili olarak ulusal ve uluslararası kılavuzlar ve öneriler yer almaktadır ${ }^{5,7-10}$. Bu kılavuzlar doğrultusunda BRT uygulamalarında da cihaz tabanlı KK testleri ERT cihazlarında olduğu gibi mekanik ve dozimetrik testler olmak üzere iki grup halinde sınıflandırılmaktadır. Cihaz tabanlı mekanik KK testleri için kaynak-pozisyon doğruluğu BRT'de dikkat edilmesi gereken en önemli fiziksel parametrelerin başında gelmektedir. BRT'de yüksek doz gradyanına bağlı olarak kaynak pozisyonundaki $3 \mathrm{~mm}$ hata \%10'un üzerinde doz farklılığına neden olabilmektedir. Kaynak pozisyon doğruluğu için tavsiye edilen üst tolerans limit ise kullanılan sisteme ve tedavi yöntemine bağlı olarak 1-2 mm’dir. Kaynak pozisyon doğruluğuna ilişkin testler cihaz üretici firması tarafından temin edilen mekanik cetvel veya film dozimetre kullanılarak otoradyografi yöntemi ile gerçekleştirilmektedir.
Çalışmamızda ise belirtilen yöntemlere ek olarak 2DArray iyon odası sisteminin kullanılabilirliği test edilmiş ve mm'nin altında hassasiyetle kaynak pozisyon doğruluğunu tespit edebileceği gösterilmiştir. Literatürde, çalışmamızla benzer şekilde Breithuth ve ark. $^{11}$ ve Kumar ve ark. ${ }^{12}$ tarafindan $2 \mathrm{D}$-Array iyon odası sisteminin kaynak pozisyon doğruluğu testi için film dozimetre yerine kullanılabileceği gösterilmiştir. Fakat bu çalışmalarda sadece kaynak pozisyon doğruluğu için ölçümler alınmış olup diğer mekanik testler analiz edilmemiştir. Cihaz tabanlı dozimetrik testlerin başında ise aktivite ölçümü gelmektedir. HDR BRT kaynaklarında aktivite ölçümüne ilişkin IAEA tarafından TECDOC 1274 no'lu rapor yayınlanmıştır ${ }^{5}$. Raporda aktivite ölçümünde kullanılması önerilen üç farklı yöntem tanımlanmıştır. Bunlar havada referans mesafede iyon odası ile ölçüm, kuyu tipi iyon odası ile ya da özel tasarlanmış fantomlar kullanılarak yapılan ölçüm yöntemleridir. Çalışmamızda ise 2D-Array iyon odası sisteminin merkezi iyon odası kullanılarak aktivite ölçümü gerçekleştirilmiştir. Ölçüm sonuçları referans iyon odası ile \%1 içerisinde uyumlu bulunmuştur. Belirsizliğin 2D-Array iyon odası sisteminin ön yüzeyinde yer alan $0,5 \mathrm{~cm}$ kalınlıkta build-up materyalinin etkisi veya detektörlerin arka yüzeyinden kaynaklı saçılmalar nedeniyle olabileceği düşünülmektedir. Ancak tüm bu belirsizlikler göz önünde bulundurulduğunda ölçülen ve hesaplanan aktivite değeri arasındaki farklılık tolerans değeri olan \%5'in altında bulunmuştur.

Hasta tabanlı KK testleri ERT'de rutin olarak gerçekleştirilirken, BRT uygulamaları için günümüzde halen standart bir yaklaşım bulunmamaktadır. Fakat yeni TPS'lerde heterojenite düzeltmesinin ve hacimsel optimizasyonun yapılabilmesi BRT uygulamalarında da hasta tabanlı KK testlerinin gerekliliğini gündeme getirmiştir. Literatürde hasta tabanlı KK testleri özel tasarlanmış jel dozimetreler kullanılarak 3 boyutlu ${ }^{13-15}$, film dozimetre ${ }^{16}$ ve $2 \mathrm{~B}$ iyon odası veya diyot detektör tabanlı sistemler ${ }^{17,18}$ kullanılarak $2 \mathrm{~B}$ veya iyon odası, termolümünesansdozimetre (TLD) ve optik uyarmalı dozimetre (OSL) gibi sistemler kullanılarak nokta doz şeklinde analiz edilmiştir ${ }^{1,19,20}$ Gelişen teknoloji ile birlikte BRT uygulamalarında da optimizasyon yöntemlerinin ve yoğunluk ayarlı BRT uygulamalarının yaygın bir şekilde kullanılmaya başlanması ile birlikte hasta tabanlı KK testleri daha da önem kazanacaktır. Bizim çalışmamızda ise Şekil 5'te gösterildiği üzere örnek bir tek kanallı tedavi planı üzerinden silindir aplikatör kullanılarak $3 \mathrm{~cm}$ derinlikte EBT3 gafkromik film dozimetreve $3,5 \mathrm{~cm}$ derinlikte 2D-Array iyon odası sistemi kullanılarak ölçümler alınmıştır. Hesaplanan ve ölçülen doz değerleri gamma analizi yöntemi kullanılarak değerlendirildiğinde 2D-Array iyon odas1 sisteminin BRT'de hasta tabanlı KK testleri için de kullanılabileceği gözlemlenmiştir. 
Çalışmamızın en önemli limitasyonları ve önerilen cözümler ise sırası ile; i) kullanılan 2D-Array iyon odası sisteminde detektörler arası mesafenin $1 \mathrm{~cm}$ olması nedeni ile kaynak yakınında özellikle doz gradyanının yüksek olduğu bölgelerde ölçümden kaynaklı belirsizlikler artacaktır. Ancak kaynaktan belirli mesafe uzaklıkta ölçümlerin alınması doz gradyanının azalmasına bağlı olarak detektörler arası interpolasyondan kaynaklı hata oranlarının minimalize edilebilmesine olanak sağlayacaktır, ii) mevcut çalışmada kullanılan planlama sistemi TG-43 formalizmine göre hesap yapması nedeni ile hasta tabanlı KK testleri sadece homojen ortamda yapılan örnek bir tedavi planı için gerçekleştirilmiştir. Bu nedenle benzer ölçümlerin heterojenite düzeltmesi yapılarak tekrarlanması gerekmektedir, iii) kaynak pozisyon doğruluğu testi için yüksek doz bölgesinin detektör merkezine gelecek şekilde kullanıcı tarafından manuel olarak kaydırılmas1 gerekmektedir ve Verisoft yazılımı otomatik olarak pozisyon hata değerini göstermemektedir. Ancak kaydırma değerini işlem esnasında sayısal olarak görmek mümkündür. Ayrıca Şekil 6.'da gösterildiği üzere Verisoft yazılımı kaynak pozisyon doğruluğu tespiti için elde edilen doz dağılımının gri skala, izodoz çizgisi veya doz boyama şeklinde analiz edilebilmesine olanak sağlamaktadır. Bu sayede film dozimetrenin getirmiş olduğu "blurring" etkisi ortadan kaldırılarak izodoz çizgisi veya doz boyama yöntemi ile pozisyon hataları daha hassas bir şekilde tespit edilebilmektedir, iv) Çalışmada aktivite ölçümü için 2D-Array iyon odası sistemi referans 0,6 cc iyon odası ile çapraz kalibrasyon yapılarak ölçümler gerçekleştirilmiştir. $\mathrm{Bu}$ nedenle benzer ölçümlerin 2D-Array iyon odası sisteminin referans koşullarda kalibre edilerek tekrarlanması çapraz kalibrasyondan kaynaklı hataların minimalize edilmesine olanak sağlayacaktır.

\section{Sonuç}

Çalışmamızın bulguları 1şığında, 2D-Array iyon odası sistemi BRT uygulamalarının rutin mekanik ve dozimetrik kontrol testleri için kullanılabilir bulunmuştur. 2D-Array tabanlı KK sistemi, testlerin tekrarlanabilirliği, uygulama ve dozimetrik değerlendirme aşamasinda standart uygulamalara göre iş yükü hafifliği ile tercih edilebilir bir sistem performansına sahiptir.

\section{Kaynaklar}

1. Nath R, Anderson LL, Meli JA, Olch AJ, Stitt JA ve Williamson JF. Code of practice for brachytherapy physics: report of the AAPM Radiation Therapy Committee Task Group No. 56. Med. Phys 1997;24(10):1557-98.

2. Skowronek J. Current status of brachytherapy in cancer treatment-short overview. J Contemp Brachytherapy 2017;9(6):581.
3. Crownover RL, Wilkinson DA ve Weinhous MS. The radiobiology and physics of brachytherapy. Hematology/oncology clinics of North America 1999;13(3):477-87.

4. Shi C, Guo B, Cheng CY, Esquivel C, Eng T ve Papanikolaou $\mathrm{N}$. Three dimensional intensity modulated brachytherapy (IMBT): dosimetry algorithm and inverse treatment planning. Med Phys 2010;37(7Part1):3725-37.

5. TECDOC, IAEA. 1274. Calibration of photon and beta ray sources used in brachytherapy. Guidelines on standardized procedures at Secondary Standards Dosimetry Laboratories (SSDLs) and Hospitals. International Atomic Energy Ageny. 2002.

6. Valentin J. Prevention of high-dose-rate brachytherapy accidents. ICRP Publication 97. Ann ICRP 2005;35(2):1-51.

7. Dempsey C, Smith R, Nyathi T, ve ark. ACPSEM brachytherapy working group recommendations for quality assurance in brachytherapy. Australas Phys Eng S 2013;36(4):387-96.

8. Venselarr $\mathrm{J}$ ve Perez-Calatayud J. European guidelines for quality assurance in radiotherapy, ESTRO Booklet No. 8, A practical guide to quality control of brachytherapy equipment." ISBN 90-804532-8 ESTRO Belgium, 2004;1-270.

9. Kutcher GJ, Coia L, Gillin M, ve ark. Comprehensive QA for radiation oncology: report of AAPM radiation therapy committee task group 40. Med Phys 1994;21(4):581-618.

10. Elfrink RJ, Kolkman-Deurloo IKK, van Kleffens HJ, ve ark. Quality control of brachytherapy equipment in the Netherlands and Belgium: current practice and minimum requirements. Radiother Oncol 2002;62(1): 95-102.

11. Breithuth F, Schiefer J, Arn M, Peters S ve Seelentag W. Determination of the source dwell position of an afterloading device with a detector array. Journal of Radiation Oncology Informatics 2017;3(1):12-24.

12. Kumar SS, Gangadharan SP, Cheruparambil AP, Parakat AT ve Perumangat A. To determine the source dwell positions of HDR brachytherapy using 2D 729 ion chamber array. Journal of Radiotherapy in Practice 2015;14(4):403-9.

13. Watanabe Y, Mizukami S, Eguchi K, ve ark. Dose distribution verification in high-dose-rate brachytherapy using a highly sensitive normoxic $\mathrm{N}$-vinylpyrrolidone polymer gel dosimeter. Phys Medica 2019;57:72-9.

14. Senkesen O, Tezcanli E, Buyuksarac B ve Ozbay I. Comparison of 3D dose distributions for HDR 192Ir brachytherapy sources with normoxic polymer gel dosimetry and treatment planning system. Med. Dosim. 2014;39(3):266-71.

15. Baldock C, De Deene Y, Doran S, ve ark. Polymer gel dosimetry. Phys Med Biol 2010;55(5):R1.

16. Palmer AL, Andrew N ve David B. Verification of high dose rate brachytherapy dose distributions with EBT3 Gafchromic film quality control techniques. Phys Med Biol 2013;58(3):497.

17. Yewondwossen M. Characterization and use of a 2D-array of ion chambers for brachytherapy dosimetric quality assurance. Med Dosim 2012;37(3):250-6.

18. Manikandan A, Biplab S, David PA, Holla R, Vivek TR ve Sujatha N. Relative dosimetrical verification in high dose rate brachytherapy using two-dimensional detector array IMatriXX. J Med Phys. 2011;36(3):171.

19. Palmer AL. Physics aspects of safety assurance in high dose rate brachytherapy: quality control testing and implementation of dosimetry audit (Doctoral dissertation, University of Surrey). 2015.

20. Kumar R, Sharma SD, Vijaykumar C, ve ark.. A dose verification method for high-dose-rate brachytherapy treatment plans. J. Cancer Res Ther 2008;4(4):173. 